This is a self-archived version of an original article. This version may differ from the original in pagination and typographic details.

Author(s): Juuti, Toni

Title: Integrated capital shares

Year: 2020

Version: Accepted version (Final draft)

Copyright: (C) 2019 Informa UK Limited, trading as Taylor \& Francis Group

Rights: In Copyright

Rights url: http://rightsstatements.org/page/lnC/1.0/?language=en

Please cite the original version:

Juuti, T. (2020). Integrated capital shares. Applied Economics Letters, 27(18), 1533-1540.

https://doi.org/10.1080/13504851.2019.1693695 


\title{
Integrated Capital Shares
}

\author{
Toni Juuti \\ University of Jyväskylä, Finland \\ toni.k.juuti@student.jyu.fi
}

ARTICLE HISTORY

Compiled November 8, 2019

\begin{abstract}
In empirical macroeconomics, inter-dependencies between countries are often analyzed using cross-country correlations or graphical investigation of time series. This study shows that applying an alternative methodological approach - identification of common unobservable factors and using them as explanatory variables for countryspecific time series - indicates a stronger cross-country integration of functional income distributions than the standard methods. The results vary only little between different samples, where both the country and year coverage change. Moreover, the main findings are not sensitive to the way capital depreciation is taken into account. The primary driving factor seems to be the same irrespective of the set of countries and time period. Furthermore, in the majority of the countries, this factor is strongly correlated with both trade openness and total factor productivity, which have been suggested to be key drivers behind the changes in the division of income between capital and labor.
\end{abstract}

\section{KEYWORDS}

Functional income distribution, Cross-country integration, Principal component analysis

\section{JEL CLASSIFICATION}

F15, F21, F62

\section{Introduction}

Recent economic literature has found that the share of national income paid to workers started to decline in the early 1980s. The suggested drivers of this evolution span from declining relative prices of investment goods (Karabarbounis and Neiman, 2013) and the rise of superstar firms (Autor et al., 2017) to the " $r>g$ dynamics" introduced by Piketty (2015). The findings are against the traditional view of a stable share, which has been one of the building blocks in many macroeconomic growth models. Furthermore, since capital income tends to be more unevenly distributed than labor income, falling labor share of income is potentially positively associated with rising levels of income inequality ${ }^{1}$. Thus, the dynamics of the functional income distribution, i.e. the division between labor and capital income, is a topic worth studying.

This work was supported by the Finnish Cultural Foundation under Grant 12181963. The data used in this study are freely available at http://www.uueconomics.se/danielw/Data.htm under "Capital shares and income inequality: Evidence from the long run", WP, (with Erik Bengtsson), 2015.

${ }^{1}$ This line of thinking is at the core of the analysis by Piketty (2015) 
This paper examines the potential inter-dependencies across capital income shares in 19 countries. The empirical analysis demonstrates that varying - including small and negative - cross-country correlations do not imply a lack of cross-country integration as common unobservable factors can explain much of the country-specific variations. Although graphical investigation of the time series show some evidence of shared patterns, the countries have not experienced rises and falls in the capital shares in tandem. Thus, the approach of this study improves on the standard analysis of interdependencies between countries. The structure of this study is the following: the next section introduces the data and methodological approach, Section 3 presents the results while Section 4 concludes the findings.

\section{Materials and methods}

Without going specifically into details on how the factor shares are estimated, two issues deserve to be discussed. First, the method for estimating the labor income of self-employed workers affects the estimates of functional income distribution. The data used in this study (Bengtsson and Waldenström, 2018) rely on the assumption that one third of the self-employed incomes are capital income while the rest is assigned to labor income ${ }^{2}$. Second, for the estimation of the capital shares net of capital depreciation, the depreciation rates need to be estimated ${ }^{3}$, which adds an additional layer of measurement uncertainty into the estimates. Consequently, the preferred specifications in this study utilize the gross shares. Since the data set adopted contains both series (with varying coverage), the sensitivity of the results is also examined ${ }^{4}$.

Figure 1 shows that for many countries the time series are characterized by a decreasing trend in the first half of the 20th century, whereas in the latter half of the sample, the capital shares rose in many countries. This does not hold universally across the countries, but on aggregate, sample mean in year 2000 has reverted back to its initial level at the early decades of the sample after a dip during the mid-decades of the last century. Thus, some traces of common patterns can be seen from graphical investigation. Since the variable of interest is defined as a share of total income, raw levels series are commensurable across countries and have a clear economic interpretation.

By construction, the capital shares take values between $0 \%$ and $100 \%$ and thus the time series are treated as stationary, which makes the approach relying on the correlation matrices meaningful. The standard cross-country correlations summarized in Tables 1 and 2 show that the pairwise correlation coefficients are predominantly positive and statistically different from zero although clear exceptions, e.g. Argentina, exist. Still, it is a demanding task to infer integration among the capital shares based on the correlations because the number of combinations is very large. More fundamentally, assuming that the potential integration is driven by a set of common global factors and allowing the country-specific capital shares to respond heterogeneously, simple correlations are unlikely to provide a comprehensive view on the inter-dependencies.

Pukthuanthong and Roll (2009) introduce a three-stage approach to identify global financial integration. First, the driving factors are identified by running a principal

\footnotetext{
${ }^{2}$ See e.g. Gollin (2002) and (Elsby et al., 2013) for a detailed discussion.

${ }^{3}$ As a specific challenge, factors such as taxation incentives may bring about volatility, non-fundamental to the distinction between gross and net capital shares, in the rates of capital depreciation.

${ }^{4}$ Depreciation may be driven by factors common across countries, especially technological development but also national accounting practices. Integration may thus arise simply as a function of common trends in depreciation. This comment by an anonymous referee is gratefully acknowledged.
} 
component analysis on either the covariance or correlation matrix. Second, a set of principal components is retained as proxies for driving factors and are used as regressors in least squares regressions, where the country-specific index returns are the dependent variables. The authors take the first 10 principal components, which capture roughly $90 \%$ of the cumulative eigenvalues, i.e. $90 \%$ of the total volatility in the correlation matrix. Finally, the $R^{2}$ values of each individual regression are collected and interpreted as the measure of integration.

For functional income distributions, let the integration between two countries, $A$ and $B$, depend on two factors, technological change $(\tau)$ and globalization $(\gamma)$. Each country's capital share of income, $y$, is given by

$$
y_{i, t}=\alpha_{i}+\beta_{i, \tau} f(\tau)_{t}+\beta_{i, \gamma} f(\gamma)_{t}+\epsilon_{i, t}
$$

where $i=A, B ; t$ refers to year, $\beta_{i, \tau}$ and $\beta_{i, \gamma}$ correspond to sensitivity parameters and $f(\tau)$ and $f(\gamma)$ are the factors driving the capital share. Pukthuanthong and Roll (2009) emphasize that even under complete integration, defined as $\epsilon_{A, t}=\epsilon_{B, t}=0$ for all $t$, the correlation between $y_{A, t}$ and $y_{B, t}$ is smaller than one if $\beta_{A, \tau} \neq k \beta_{B, \tau}$ or $\beta_{A, \gamma} \neq k \beta_{B, \tau}$ for some positive scalar $k$. In other words, perfect integration, as defined above, does not imply perfect correlation.

\section{Results}

In Tables 1 and 2, six principal components is sufficient to explain $90 \%$ of the total volatility in the cross-country correlations (Table 3 and Figure 2). In the set of 19 countries (years 1960-2000), the first factor captures more than half of the cumulative value, whereas in the sample of 11 countries (1929-2000), the relative importance of the factors 3-6 is higher. The aim of the study is not to determine the underlying drivers of the division of income between labor and capital but to rather introduce a novel way to examine macroeconomic inter-dependencies. However, one way to interpret the factors extracted from the data generating processes of the capital shares is to compare the factors to some candidate driving factors. Considering the trade openness measure of Fouquin and Hugot (2016), the sum of imports and exports relative to GDP, and the measure of technological progress of the Penn World Table (Feenstra et al., 2015), total factor productivity, reveals that the first factor is positively correlated with these two potential drivers of the functional income distribution in many countries.

The six principal components for the two samples, 19 countries in a period 19602000 and 11 countries in a period 1929-2000, are presented in Figure 3. The first factors of the two samples that capture $54 \%$ and $38 \%$ of the cumulative eigenvalues, respectively, seem to follow one another very closely in the overlapping period 19602000. A correlation coefficient of 0.96 implies that the primary driving factor is the same irrespective of the sample. The same is not true for the five other factors as the pairwise correlations between the ordered factors are $-0.86,-0.22,0.13,0.29$ and 0.24 . The first factor, which follows the suggested observable drivers in many countries as discussed above, seems to stand out from the others throughout the empirical analysis. Since in the forthcoming least squares regressions the six factors enter as regressors and the objective is to collect the country-specific $R^{2}$ values, multicollinearity is a potential issue. Beneficially, the correlations between the factors are minuscule irrespective of the sample.

Figure 4 summarizes the evidence of integration across the country-specific capital 
shares ${ }^{5}$. The $R^{2}$ values are predominantly 0.9 or higher while the lowest value is 0.85. To investigate the robustness of the results, the turbulent years 1929-1945 are excluded (Table 4 column (3)), capital shares net of depreciation are considered (Table 4 columns (4) and (5), Table 5 columns (3) and (4)) and the countries that do not have data for 2001-2010 are dropped to include the most recent years possible (Table $5)$. In brief, the results show only little sensitivity between the samples.

As discussed in Pukthuanthong and Roll (2009), the multi-factor $R^{2}$ measure of integration may have some weaknesses beyond the interpretation of factors. First, and not limited to this specific technique, the countries that Bengtsson and Waldenström (2018) have data on are likely to be more integrated to the global economic system than many countries for which there are no data on capital shares. In other words, there may be a selection issue and thus claiming that the results of this study imply a global integration of functional income distribution may be an exaggerated statement. Perhaps, integration among developed countries is an apt depiction of the main finding even though Argentina and Brazil are included in the analysis. Second, the derived factors may well be country-specific instead of "global" even if the $R^{2}$ values for individual countries were large. As a simple example, Pukthuanthong and Roll (2009) consider two countries and two estimated global factors. If the exposures to the factors are $(1,0)$ for country $\mathrm{A}$, and $(0,1)$ for country $\mathrm{B}$, the integration measure may indicate complete integration even though, in reality, the countries are completely non-integrated as they respond to disparate global shocks.

In the sample of 19 countries, the first factor as a sole regressor yields an $R^{2}$ higher than 0.5 for 13 countries and a value higher than 0.8 for four countries. The countries whose capital shares seem to have been driven by other factors are Argentina $\left(R^{2}=0.23\right)$, Belgium (0.06), Brazil (0.18), Canada (0.04), Denmark (0.18) and Japan (0.02). Argentina and Brazil are clear exceptions from the rest in terms of the level of economic development, Japan experienced economic stagnation during the final decade of the sample and is the only Asian economy in the sample, whereas Belgium, Canada and Denmark are not apparently different from for example Netherlands, the other Anglo-American countries and the Nordic welfare states, respectively. As a speculative conclusion, these countries may possess some nation-specific institutional traits that partly detach them from evolutions driven by e.g. the expansion of trade and technological progress. The number of countries for which the $R^{2}$ rises over 0.5 drops to four in a single-factor model for the period 1929-2000. This suggests that the role of the first factor as a determinant of integration of the capital shares has increased over time. In Australia, Sweden and the United Kingdom, the role of the first factor seems to be particularly strong irrespective of the time period as the single-factor $R^{2}$ is roughly 0.7 .

\section{Discussion}

This study has investigated the cross-country inter-dependencies of functional income distributions in 19 countries that are mostly developed OECD member states. The methodological approach relies on principal component analysis to evaluate how well unobservable common factors can explain the capital shares of total national income. A set of six factors can capture more than $90 \%$ of the total volatility in the correlation matrix of the country-specific capital shares. Using the factors as regressors for the

\footnotetext{
${ }^{5}$ The correlation matrices, principal component analyses and detailed regression outputs for all samples can
} be reproduced using the supplementary materials. 
country-specific capital shares in least squares regressions yields high $R^{2}$ values, which indicates that common factors are driving the national functional income distributions. Such a high level of integration seems not to exist if only standard correlations and graphical analysis on the time series are considered. Under strong integration, policy actions aiming to influence national functional income distributions are potentially less effective than under country-specific dynamics.

Acknowledgments: I greatly benefited from the help of Vance Martin on the methodological approach and the valuable comments by Juha Junttila.

Declaration of interest: none

\section{References}

Autor, D., Dorn, D., Katz, L. F., Patterson, C., and Van Reenen, J. (2017). The fall of the labor share and the rise of superstar firms. IZA Discussion Paper Series.

Bengtsson, E. and Waldenström, D. (2018). Capital shares and income inequality: Evidence from the long run. The Journal of Economic History, 78(3):712-743.

Elsby, M. W., Hobijn, B., and Şahin, A. (2013). The decline of the us labor share. Brookings Papers on Economic Activity, 2013(2):1-63.

Feenstra, R. C., Inklaar, R., and Timmer, M. P. (2015). The next generation of the penn world table. American economic review, 105(10):3150-82.

Fouquin, M. and Hugot, J. (2016). Two centuries of bilateral trade and gravity data: 1827-2014. Technical report, Universidad Javeriana-Bogotá.

Gollin, D. (2002). Getting income shares right. Journal of Political Economy, 110(2):458-474.

Karabarbounis, L. and Neiman, B. (2013). The global decline of the labor share. The Quarterly Journal of Economics, 129(1):61-103.

Piketty, T. (2015). About capital in the twenty-first century. American Economic Review, 105(5):48-53.

Pukthuanthong, K. and Roll, R. (2009). Global market integration: An alternative measure and its application. Journal of Financial Economics, 94(2):214-232. 
Table 1. Standard cross-country correlations in the sample 1960-2000 (Pearson correlation coefficient)

\begin{tabular}{|c|c|c|c|c|c|c|c|c|c|c|c|c|c|c|c|c|c|c|c|}
\hline & ARG & AUS & AUT & BEL & BRA & CAN & DNK & FIN & FRA & DEU & IRL & JPN & NLD & NZL & NOR & ESP & SWE & GBR & USA \\
\hline ARG & 1.00 & & & & & & & & & & & & & & & & & & \\
\hline AUS & -0.40 & 1.00 & & & & & & & & & & & & & & & & & \\
\hline AUT & -0.40 & 0.84 & 1.00 & & & & & & & & & & & & & & & & \\
\hline BEL & -0.42 & -0.21 & -0.14 & 1.00 & & & & & & & & & & & & & & & \\
\hline BRA & 0.23 & 0.47 & 0.38 & -0.86 & 1.00 & & & & & & & & & & & & & & \\
\hline CAN & 0.17 & 0.04 & 0.08 & -0.57 & 0.43 & 1.00 & & & & & & & & & & & & & \\
\hline DNK & -0.54 & 0.26 & 0.38 & 0.50 & -0.49 & -0.25 & 1.00 & & & & & & & & & & & & \\
\hline FIN & -0.44 & 0.57 & 0.70 & -0.17 & 0.29 & 0.34 & 0.32 & 1.00 & & & & & & & & & & & \\
\hline FRA & -0.37 & 0.92 & 0.83 & -0.23 & 0.56 & -0.07 & 0.18 & 0.53 & 1.00 & & & & & & & & & & \\
\hline DEU & -0.38 & 0.88 & 0.86 & -0.26 & 0.50 & 0.12 & 0.27 & 0.62 & 0.86 & 1.00 & & & & & & & & & \\
\hline IRL & -0.22 & 0.80 & 0.81 & -0.43 & 0.63 & 0.24 & 0.23 & 0.68 & 0.81 & 0.90 & 1.00 & & & & & & & & \\
\hline JPN & -0.33 & 0.00 & 0.00 & 0.84 & -0.62 & -0.63 & 0.28 & -0.12 & -0.02 & -0.16 & -0.31 & 1.00 & & & & & & & \\
\hline NLD & -0.50 & 0.66 & 0.82 & 0.19 & -0.03 & -0.06 & 0.66 & 0.50 & 0.63 & 0.71 & 0.55 & 0.18 & 1.00 & & & & & & \\
\hline NZL & -0.71 & 0.76 & 0.69 & 0.16 & 0.04 & -0.06 & 0.59 & 0.64 & 0.67 & 0.72 & 0.63 & 0.21 & 0.68 & 1.00 & & & & & \\
\hline NOR & -0.36 & 0.68 & 0.73 & -0.35 & 0.34 & 0.35 & 0.38 & 0.57 & 0.53 & 0.68 & 0.65 & -0.26 & 0.67 & 0.60 & 1.00 & & & & \\
\hline ESP & -0.20 & 0.80 & 0.89 & -0.45 & 0.58 & 0.28 & 0.25 & 0.68 & 0.82 & 0.84 & 0.86 & -0.33 & 0.70 & 0.55 & 0.74 & 1.00 & & & \\
\hline SWE & -0.44 & 0.78 & 0.79 & -0.24 & 0.31 & 0.25 & 0.40 & 0.60 & 0.71 & 0.73 & 0.62 & -0.19 & 0.74 & 0.65 & 0.77 & 0.81 & 1.00 & & \\
\hline GBR & -0.49 & 0.73 & 0.84 & 0.01 & 0.20 & 0.26 & 0.41 & 0.71 & 0.68 & 0.81 & 0.73 & 0.02 & 0.78 & 0.75 & 0.59 & 0.76 & 0.74 & 1.00 & \\
\hline USA & -0.38 & 0.68 & 0.65 & -0.14 & 0.16 & 0.12 & 0.52 & 0.37 & 0.55 & 0.78 & 0.67 & -0.22 & 0.70 & 0.64 & 0.70 & 0.66 & 0.73 & 0.71 & 1.00 \\
\hline
\end{tabular}


Table 2. Standard cross-country correlations in the sample 1929-2000 (Pearson correlation coefficient)

\begin{tabular}{|c|c|c|c|c|c|c|c|c|c|c|c|}
\hline & $\mathrm{ARG}$ & AUS & BRA & CAN & DNK & FIN & FRA & ESP & SWE & GBR & USA \\
\hline ARG & 1.00 & & & & & & & & & & \\
\hline AUS & -0.32 & 1.00 & & & & & & & & & \\
\hline BRA & 0.43 & 0.39 & 1.00 & & & & & & & & \\
\hline $\mathrm{CAN}$ & 0.29 & -0.19 & 0.25 & 1.00 & & & & & & & \\
\hline DNK & -0.59 & 0.48 & -0.45 & -0.27 & 1.00 & & & & & & \\
\hline FIN & -0.09 & 0.76 & 0.45 & -0.10 & 0.40 & 1.00 & & & & & \\
\hline FRA & -0.15 & 0.67 & 0.54 & -0.04 & 0.12 & 0.64 & 1.00 & & & & \\
\hline ESP & -0.41 & 0.02 & -0.21 & -0.06 & 0.22 & -0.28 & -0.01 & 1.00 & & & \\
\hline SWE & -0.54 & 0.68 & -0.08 & 0.00 & 0.76 & 0.44 & 0.32 & 0.43 & 1.00 & & \\
\hline GBR & -0.58 & 0.56 & 0.01 & 0.02 & 0.52 & 0.44 & 0.53 & 0.50 & 0.70 & 1.00 & \\
\hline USA & -0.12 & -0.01 & 0.03 & 0.30 & 0.08 & -0.10 & 0.13 & 0.40 & 0.28 & 0.46 & 1.00 \\
\hline
\end{tabular}


Table 3. Eigenvalues of the principal component analyses using Table 1 (1960-2000) and Table 2 (1929-2000)

\begin{tabular}{cccccccc}
\multicolumn{2}{c}{ Sample: $1960-2000$} & \multicolumn{5}{c}{ Sample: 1929-2000 } \\
\hline Eigenvalue & Value & $\begin{array}{c}\text { Cumulative } \\
\text { value }\end{array}$ & $\begin{array}{c}\text { Cumulative } \\
\text { proportion }\end{array}$ & $\begin{array}{c}\text { Eigenvalue } \\
\text { Value }\end{array}$ & $\begin{array}{c}\text { Cumulative } \\
\text { value }\end{array}$ & $\begin{array}{c}\text { Cumulative } \\
\text { proportion }\end{array}$ \\
\hline 1 & 10.2509 & 10.2509 & 0.5395 & 1 & 4.1762 & 4.1762 & 0.3797 \\
2 & 3.9409 & 14.1918 & 0.7469 & 2 & 2.5058 & 6.6820 & 0.6075 \\
3 & 1.3238 & 15.5156 & 0.8166 & 3 & 1.7068 & 8.3887 & 0.7626 \\
4 & 0.8811 & 16.3966 & 0.8630 & 4 & 0.8493 & 9.2380 & 0.8398 \\
5 & 0.6037 & 17.0003 & 0.8948 & 5 & 0.5274 & 9.7654 & 0.8878 \\
6 & 0.4815 & 17.4818 & 0.9201 & 6 & 0.4716 & 10.2370 & 0.9306 \\
7 & 0.4405 & 17.9223 & 0.9433 & 7 & 0.2748 & 10.5118 & 0.9556 \\
8 & 0.3058 & 18.2281 & 0.9594 & 8 & 0.2178 & 10.7296 & 0.9754 \\
9 & 0.2296 & 18.4578 & 0.9715 & 9 & 0.1321 & 10.8617 & 0.9874 \\
10 & 0.1593 & 18.6171 & 0.9798 & 10 & 0.0780 & 10.9397 & 0.9945 \\
11 & 0.0964 & 18.7135 & 0.9849 & 11 & 0.0603 & 11.0000 & 1.0000 \\
12 & 0.0830 & 18.7965 & 0.9893 & & & & \\
13 & 0.0538 & 18.8503 & 0.9921 & & & & \\
14 & 0.0434 & 18.8937 & 0.9944 & & & & \\
15 & 0.0343 & 18.9280 & 0.9962 & & & & \\
16 & 0.0247 & 18.9527 & 0.9975 & & & & \\
17 & 0.0226 & 18.9753 & 0.9987 & & & & \\
18 & 0.0138 & 18.9891 & 0.9994 & & & & \\
19 & 0.0109 & 19.0000 & 1.0000 & & & & \\
\hline
\end{tabular}


Table 4. Integration measures for samples that cover the years 1960-2000, 1946-2000 and 1929-2000

The $R^{2}$ values are collected from least squares regression, where the country-specific capital shares are regressed on unobservable factors that capture just over $90 \%$ of the cumulative eigenvalues of the cross-country correlation matrix. Columns (1) and (2) collect the integration measures of the samples under detailed investigation. The sample of column (3) excludes the years of the Great Recession and the Second World War. Columns (1)-(3) correspond to capital share time series gross of capital depreciation (Gross) while columns (4) and (5) take depreciation into account (Net). Six factors are needed to explain $90 \%$ of the variation in the cross-country correlation matrix for columns (1)-(4). For column (5), five factors are sufficient.

\begin{tabular}{|c|c|c|c|c|c|}
\hline & (1) & (2) & (3) & (4) & (5) \\
\hline Capital share & Gross & Gross & Gross & Net & Net \\
\hline Time period & $1960-2000$ & $1929-2000$ & $1946-2000$ & $1960-2000$ & $1929-2000$ \\
\hline Number of countries & 19 & 11 & 11 & 17 & 9 \\
\hline \multicolumn{6}{|l|}{ Country } \\
\hline Argentina & 0.92 & 0.92 & 0.83 & & \\
\hline Australia & 0.93 & 0.90 & 0.95 & 0.89 & 0.86 \\
\hline Austria & 0.94 & & & 0.90 & \\
\hline Belgium & 0.96 & & & 0.94 & \\
\hline Brazil & 0.97 & 0.93 & 0.93 & & \\
\hline Canada & 0.90 & 0.99 & 0.97 & 0.85 & 0.98 \\
\hline Denmark & 0.90 & 0.95 & 0.89 & 0.82 & 0.92 \\
\hline Finland & 0.90 & 0.90 & 0.93 & 0.92 & 0.90 \\
\hline France & 0.96 & 0.88 & 0.93 & 0.95 & 0.96 \\
\hline Germany & 0.93 & & & 0.93 & \\
\hline Ireland & 0.96 & & & 0.95 & \\
\hline Japan & 0.93 & & & 0.92 & \\
\hline Netherlands & 0.93 & & & 0.92 & \\
\hline New Zealand & 0.90 & & & 0.94 & \\
\hline Norway & 0.85 & & & 0.84 & \\
\hline Spain & 0.94 & 0.96 & 0.96 & 0.89 & 0.99 \\
\hline Sweden & 0.90 & 0.94 & 0.90 & 0.95 & 0.93 \\
\hline United Kingdom & 0.87 & 0.88 & 0.89 & 0.92 & 0.86 \\
\hline United States & 0.90 & 0.98 & 0.98 & 0.86 & 0.97 \\
\hline Average $R^{2}$ & 0.92 & 0.93 & 0.92 & 0.91 & 0.93 \\
\hline
\end{tabular}


Table 5. Integration measures for samples that cover the years 1960-2010 and 1929-2010

The $R^{2}$ values are collected from least squares regression, where the country-specific capital shares are regressed on unobservable factors that capture just over $90 \%$ of the cumulative eigenvalues of the cross-country correlation matrix. Columns (1) and (2) correspond to capital share time series gross of capital depreciation (Gross) while columns (3) and (4) take depreciation into account (Net). Six factors are needed to explain $90 \%$ of the variation in the cross-country correlation matrix for column (3). For columns (1), (2) and (4), five factors are sufficient. For 2001-2010, the data are missing for Argentina, Brazil and Spain.

\begin{tabular}{lcccc}
\hline & $(1)$ & $(2)$ & $(3)$ & $(4)$ \\
\hline Capital share & Gross & Gross & Net & Net \\
Time period & $1960-2010$ & $1929-2010$ & $1960-2010$ & $1929-2010$ \\
Number of countries & 16 & 8 & 16 & 8 \\
\hline Country & & & & \\
Australia & 0.95 & 0.86 & 0.95 & 0.85 \\
Austria & 0.95 & & 0.90 & \\
Belgium & 0.96 & & 0.95 & \\
Canada & 0.92 & 0.99 & 0.89 & 0.98 \\
Denmark & 0.94 & 0.93 & 0.92 & 0.95 \\
Finland & 0.94 & 0.97 & 0.93 & 0.93 \\
France & 0.95 & 0.91 & 0.95 & 0.93 \\
Germany & 0.95 & & 0.94 & \\
Ireland & 0.90 & & 0.91 & \\
Japan & 0.94 & & 0.95 & \\
Netherlands & 0.89 & & 0.89 & \\
New Zealand & 0.89 & & 0.90 & \\
Norway & 0.87 & & 0.86 & 0.97 \\
Sweden & 0.81 & 0.93 & 0.97 & 0.93 \\
United Kingdom & 0.80 & 0.86 & 0.83 & 0.96 \\
United States & 0.92 & 0.98 & 0.87 & 0.94 \\
\hline Average $R^{2}$ & 0.91 & 0.93 & 0.91 & \\
\hline
\end{tabular}




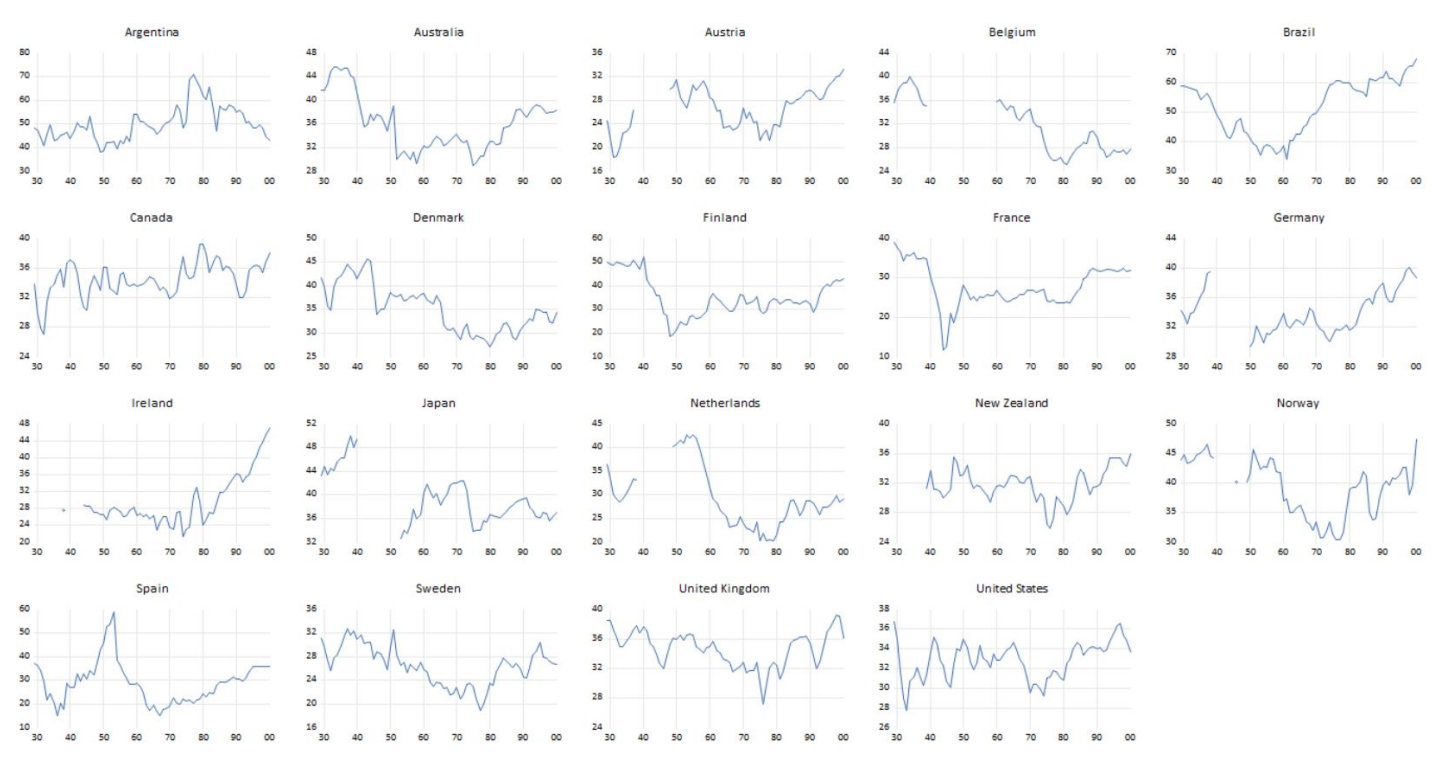

Figure 1.

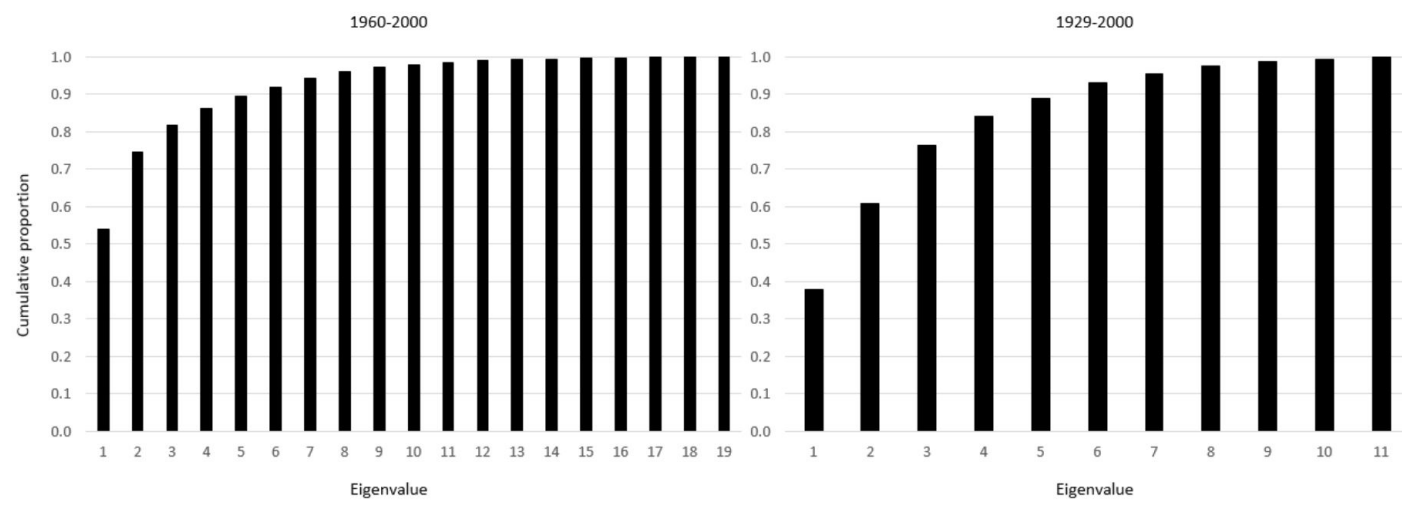

Figure 2. 


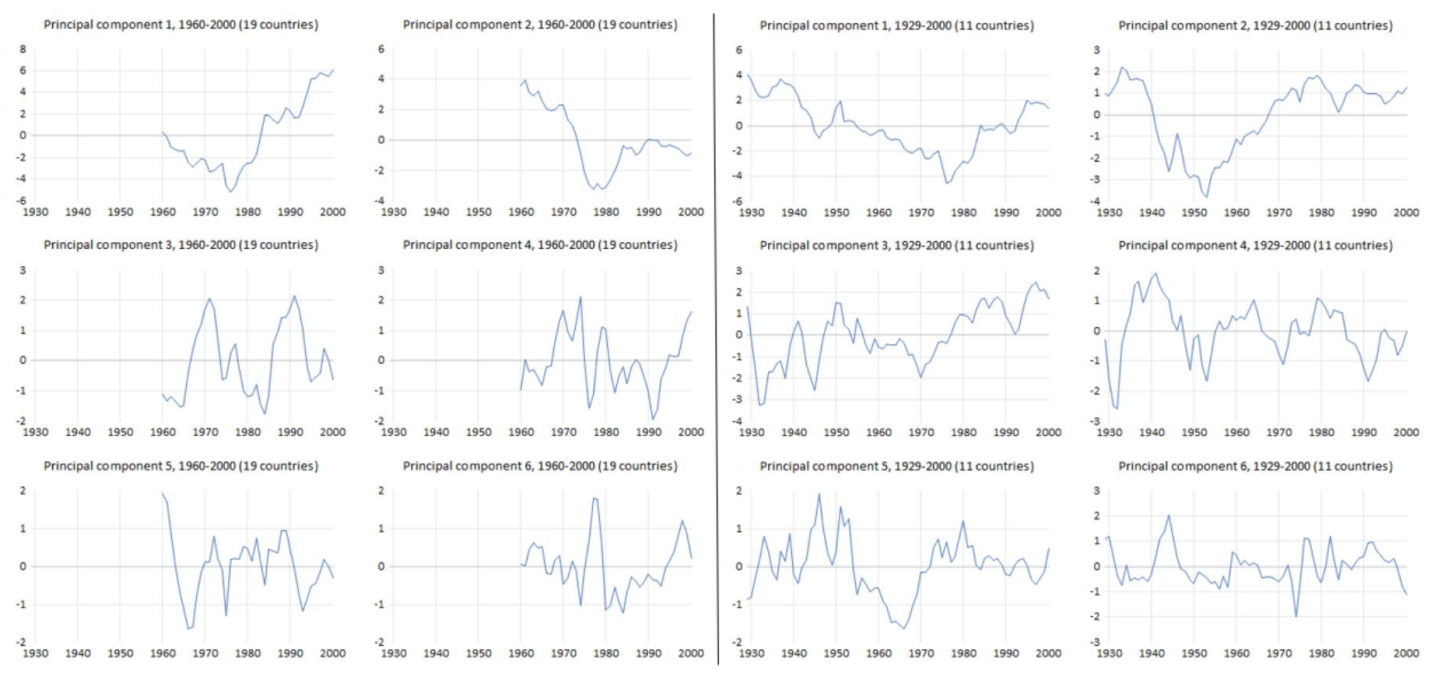

Figure 3.

1960-2000
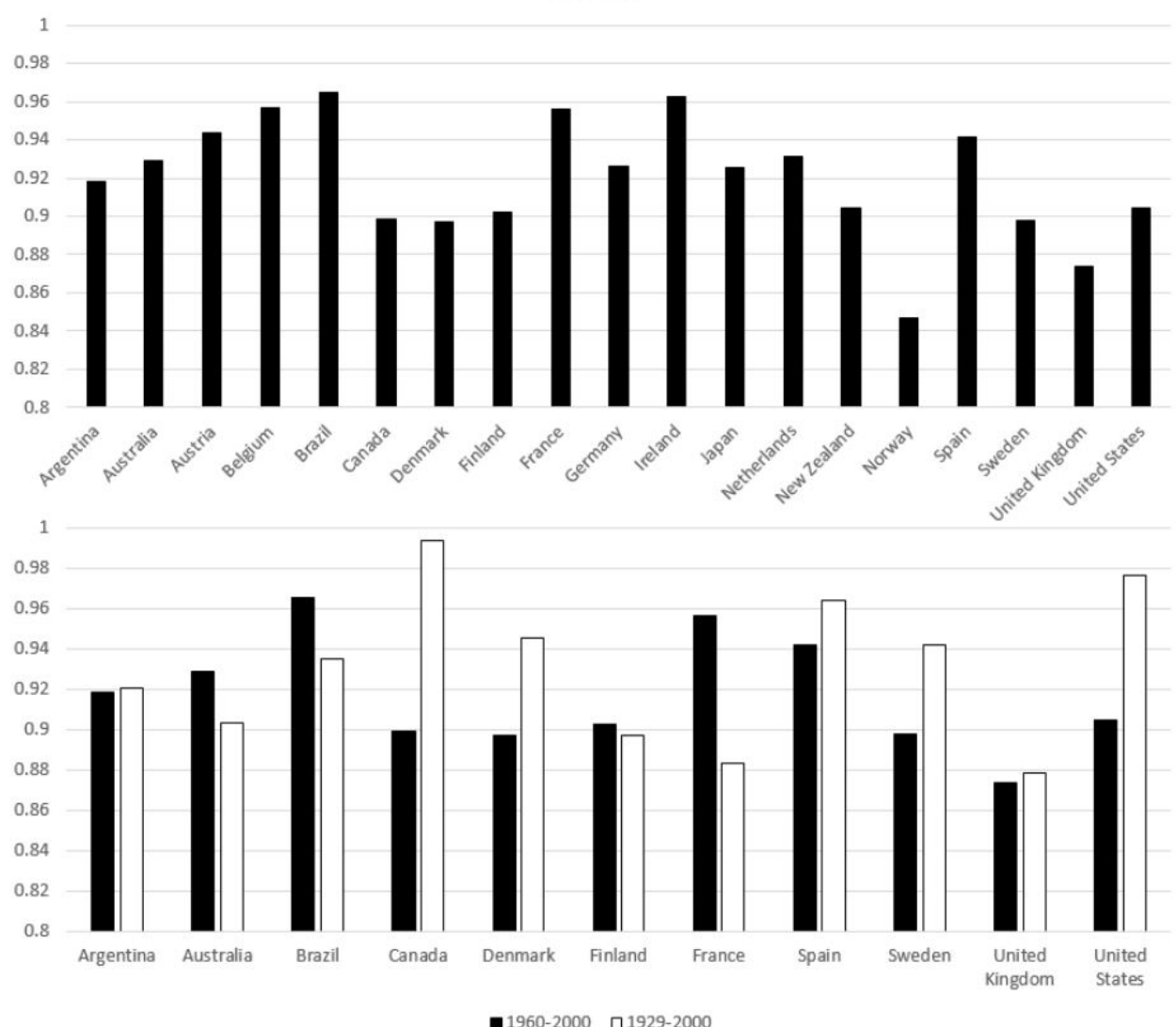

Figure 4. 


\section{List of Figures}

Figure 1. Capital shares (gross of capital depreciation, \%) over the 20th century in the sample of 19 countries (Bengtsson and Waldenström,

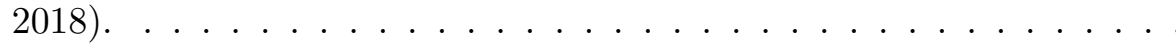

Figure 2. Cumulative percentage of the total variance of the correlation matrix explained by sorted eigenvalues. . . . . . . . . . .

ure 3. The evolution of the six principal components in the samples of

19 (1960-2000) and 11 countries (1929-2000). . . . . . . . . . .

Figure 4. Measures of integration (Pukthuanthong and Roll, 2009) in the samples of 19 (1960-2000) and 11 countries (1929-2000). Countryspecific capital shares regressed on unobservable factors that capture just over $90 \%$ of the cumulative eigenvalues of the cross-country correlation matrix. . . . . . . . . . . . . . 